\title{
Food consumption behaviours and associated personal and socio-economic factors in elderly adults, Northeastern Thailand
}

\author{
Pruksa Supannee*
}

Faculty of Science and Technology, Loei Rajabhat University, Loei, Thailand

\begin{abstract}
Introduction: This research was a cross-sectional study. The objective was to study food consumption behaviours and associated factors in elderly adults in the Northeastern Region. Methods: The study included 1,336 older adults (age $>60$ years) from five provinces, i.e. Udornthani, Nakornratchasima, Mahasarakam, Nakhonpanom and Amnatcharoen. Random multi-stage sampling was used, and data were collected through interview. The statistics used for content analysis was percentage, mean, standard deviation $(S D)$ and multiple logistic regression analysis. Results: The food consumption behaviours of the study population was fair or poor $(60.0 \%)$, followed by good $(40.0 \%)$. Multiple logistic regression revealed that there were some personal factors that were significantly associated with food consumption behaviours. These factors included sex, education level, living condition, health condition, knowledge, attitude and preference of food. Regarding the effect of socioeconomic factors towards food consumption behaviours, it was found that those effects included food sources and food factors. Conclusion: Local health authorities should pay attention to the factors mentioned above in order to designate policies or methods to oversee future food consumption behaviours in the elderly.
\end{abstract}

Keywords: Food consumption behaviours, factors, elderly, Thailand

\section{INTRODUCTION}

Thailand faced a tremendous change in its population structure since 2005 when it entered the Aged Society. Ten percent of the Thai population is over 60 years old and this number is likely to grow. In 2017, $17 \%$ of the Thai population was aged. It has been predicted that Thailand will be a Complete Aged Society in 2021, which means that the aged population will increase by $20 \%$ and Thailand will become a Super Aged Society in 2035. It is estimated that the aged population will be $30 \%$ of all Thai population then. The progression towards an aged society in Thailand is a result of decreased birth rate and increased longevity among people, in addition to decreased death rate. These factors are consequences of advanced medical technology within the field of public health in Thailand (Sangthong, 2017).

As people age, the risk of ill health increases, especially with regards to non-communicable diseases. The reason is that the elderly's body deteriorates physically, mentally and socially (Jones \& Boelaert, 2015). Noncommunicable diseases are connected to food consumption behaviours (Rauber

\footnotetext{
*Corresponding author: Supannee Pruksa

Faculty of Science and Technology, Loei Rajabhat University, Loei, Thailand

Tel: (66)42835223-8 ext 41110 E-mail: supannee.pru@gmail.com

doi: https://doi.org/10.31246/mjn-2019-0095
} 
et al., 2018). When older adults have appropriate dietary intakes, their health will be better, thus more able to slow down symptoms of non-communicable diseases. On the other hand, if older adults do not have appropriate and healthy foods, they may succumb to malnutrition (under- and overnutrition). According to a survey by the National Statistics Office, under 50\% of the elderly who were $>60$ years old reported themselves to be in good health (Aekplakorn \& Satheannoppakao, 2012). The fifth physical examination, conducted in 2014 by the Office for the Survey of Thai Population Health under the Institute of Public Health Survey, found that the elderly were at risk of heart and blood system diseases, i.e. hypertension at $53.2 \%$, diabetes at $18.1 \%$, overweight $\left(\mathrm{BMI} \geq 25 \mathrm{~kg} / \mathrm{m}^{2}\right)$ at $35.4 \%$, obesity at $49.4 \%$ and metabolic syndrome at $46.8 \%$. Regarding chronic diseases, it was found that a quarter of the elderly (about 2.2 million people) had knee arthrosis, followed by gout $(5.4 \%)$, and heart attack (4.6\%). It is common to find that anaemia comes with age. Around $48 \%$ of the elderly who are $>80$ years old has anaemia (Aekplakorn \& Satheannoppakao, 2012). As a result, nutrition in the elderly should be looked at very closely and carefully because it could affect an elderly person's health in the future. In addition, appropriate food consumption behaviours could prevent diseases and increase longevity.

From a recent survey on the nutritional state of Thai elderly, it was found that at least half of the respondents did not have three meals a day. Only $29.1 \%$ of elderly aged $>70$ years old and $11.4 \%$ of elderly aged over 80 years old consumed enough portions of fruits and vegetables daily (Aekplakorn, 2014). Moreover, the elderly tended to eat lesser protein, calcium, vitamin A, and fibre, especially in the Northeastern region of Thailand (Aekplakorn \&
Satheannoppakao, 2012). Physical changes associated with ageing, such as problems related to the digestion system, chewing, swallowing and also food preferences are important causal factors of malnutrition in the elderly (Ahmed \& Haboubi, 2010). In addition, society has been changing rapidly, and the gain in popularity of social media has increased foreign culture accessibility including Western foods. In fact, food behaviours of Thai people has changed from the past and consumption of fast foods has been on the rise (Warathornpiboon, 2014; Pruksa \& Sripoona, 2017). Many factors have been associated with the food consumption behaviours of Thai people, such as a lack of knowledge, false beliefs, incorrect information, abandonment from children, and social status of the elderly (Kitreerawutiwong \& Mekrungrongwong, 2016).

Based on the findings described above, it is necessary to improve food consumption behaviours among the elderly, and to increase their awareness of the link between their diet and health. Such an approach could also decrease the risks of under- and overnutrition, especially among the elderly in the Northeastern region of Thailand. Malnutrition among the elderly in this region is a particularly significant problem, because nutrient intakes in these elderly are below average (Aekplakorn \& Satheannoppakao, 2012), and this region is home to the largest number of elderly in the country (Foundation of Thai Gerontology Research and Development Institute, 2017). Therefore, the aim of this study was to determine food consumption behaviours and associated factors among elderly adults living in the Northeastern region of Thailand. The data obtained from this study will be used to solve the food consumption behaviour problems, improve the nutritional status of the elderly, plan activities to promote health 
of the elderly, and improve their food consumption behaviours so that they can have better health in the future.

\section{MATERIALS AND METHODS}

\section{Sample selection and subjects}

Multistage cluster sampling was applied to obtain a sample which was representative of the Northeastern Thai elderly population, based on the overall Thai population from the Department of Provincial Administration. For the first stage, five provinces were randomly sampled by proportion to size from each of the five Northeastern provincial clusters. In the second stage, 2-8 districts were randomly selected by proportion to size from each province. In the third stage, two villages were randomly selected by proportion to size from urban and rural areas in each province. In the final stage, elderly adults were randomly selected by proportion to size from each village.

Subjects were 1,336 elderly people. This was computed using the formula for a single proportion with an expected prevalence of 0.06-0.45 with an error of $5 \%$ at $95 \%$ confidence interval (CI). In order for subjects to be able to participate in this study, a set of inclusion criteria was followed. The participants were required to be reliable and willing to take part in this study. Before the start of the study, the objectives were carefully explained to the subjects. Informed consent was then obtained from all subjects.

\section{Questionnaire and data collection}

Information about food consumption behaviours and related factors were collected using an intervieweradministered questionnaire, which was developed by the author (Cronbach's $\alpha=$ 0.83). The questionnaire consisted of six parts: demographic and socioeconomic factors, food sources, food factors, food culture, knowledge towards food consumption, attitude and preference towards food consumption, and food consumption behaviours. The questionnaire covered the sources of foods that the elderly usually consume. Food factors meant easy or convenient accessibility of food sources, as well as quality, taste, nutritive value, and safety of food sources, in addition to appropriate and stable prices of foods. Food preference referred to how much the elderly liked or disliked different types of foods. Binary-choice questions were used for food culture and its total score equaled to 16 . A ten-item test was used for knowledge. A score was given for each correctly answered question. A 3-rating scale questionnaire was used for attitude and food preferences, family relations, and food factors. The total scores for these questions equaled to $24,27,9$, and 24 , respectively. The questionnaire on food consumption behaviours covered meals and five food groups, foods that the elderly should consume, foods that the elderly should avoid, cooking, purchasing, and changes in food behaviours. A 4-rating scale for response was used for food consumption behaviours. The total score equaled to 148. Those were then classified into three levels (poor, fair, and good) according to Best (1977), except for knowledge, which was classified according to Bloom (1971). For food consumption behaviours, a good level was used as a cut-off point for categorical data (i.e. total score >112). Data were collected by trained research assistants with a manual for data collection. These were individuals who had knowledge on food and nutrition or health, namely nutritionists, community dietitians, nurses, and public health officers. Elderly participants were asked about their food consumption patterns and to recall how often they consumed foods or meals during the past month. Collection of some information was 
randomly repeated by food and nutrition experts, in order to ensure that highquality data were obtained within a week.

\section{Ethical considerations}

The research protocol was approved by the Ethics Committee of Loei Rajabhat University. All participants gave their written consent, and voluntarily cooperated and partook in the research. Before signing the consent form, participants had been told about the objectives of the research, the research methodology and also the benefits of the research. They could choose whether to join the research or not, or withdraw from the research without giving any reasons. Their information were kept confidential. The researcher did not harm the participants, and the researcher did not benefit from them at all.

\section{Data analysis}

Data were analysed using descriptive statistics (percentage, mean, standard deviation $(S D)$ for food consumption behaviours and related factors. Multiple logistic regression was carried out for categorical data to determine the factors associated with food consumption behaviours of elderly in Northeastern Thailand.

\section{RESULTS}

Table 1 shows that $40.0 \%$ of respondents had "good" food consumption behaviour and 60.0\% had "fair or poor" food consumption behaviour. The mean $\pm S D$ score for food consumption behavior score was $103.84 \pm 15.59$.

Table 2 shows the characteristics of the elderly and the distribution of factors. The mean $\pm S D$ for age of the subjects was $68.01 \pm 6.86$ years $(58.6 \%$ females and $41.4 \%$ males). The majority of them were married $(61.83 \%)$, had a primary education or lesser (62.1\%), lived with their family $(95.4 \%)$, and took care of themselves (93.1\%). Half of them had an income of $<3,000$ Thai Baht (98 USD) per month. Around 68\% declared that their incomes were sufficient and enough for savings. Three quarter $(74.7 \%)$ of the households had 3-4 family members. Over half $(53.8 \%)$ of the family members were responsible for caring for the elderly, and $91.6 \%$ had a good relationship with the elderly. The proportion of the elderly that had a good level of knowledge about food and nutrition amounted to $54.1 \%$. Almost two thirds (62.7\%) had a "good" attitude towards food consumption, and $41.7 \%$ had a "good" preference towards food consumption. The proportion of elderly who had a good level of culture around food consumption was $78.7 \%$. It was found that $93.0 \%$ of the elderly had access to health information. Moreover, $49.4 \%$ of respondents consumed foods that were obtained from the village market, $20.2 \%$ consumed foods taken from their own garden, and $13.9 \%$ ate foods purchased from the market in town. In addition, $79.6 \%$ of respondents scored a good level for food factors.

Binary logistic regression showed that personal factors related to food

Table 1. Distribution of food consumption behaviours among the elderly residing in Northeastern Thailand $(N=1,336)$

\begin{tabular}{lccc}
\hline Food consumption behaviours & $n$ & $\%$ & Mean \pm SD \\
\hline Good & 534 & 40.0 & \\
Fair or poor & 802 & 60.0 & \\
Food consumption behaviour score & & & $103.84 \pm 15.59$ \\
\hline
\end{tabular}


Table 2. Distribution of factors and binary logistic regression of factors influencing food consumption behaviours $(N=1,336)$

\begin{tabular}{|c|c|c|c|c|c|}
\hline \multirow[b]{2}{*}{ Factors } & \multirow[b]{2}{*}{$n(\%)$} & \multicolumn{2}{|c|}{ Behaviour } & \multirow{2}{*}{$\begin{array}{c}\text { Good behaviour } \\
\text { Crude OR } \\
\text { (95\% CI) }\end{array}$} & \multirow[b]{2}{*}{ p-value } \\
\hline & & $\begin{array}{c}\text { Good } \\
\%\end{array}$ & $\begin{array}{c}\text { Fair or poor } \\
\%\end{array}$ & & \\
\hline \multicolumn{6}{|l|}{ Personal Factors } \\
\hline \multicolumn{6}{|l|}{ Sex } \\
\hline Male & $553(41.4)$ & 66.2 & 33.8 & & \\
\hline Female & $783(58.6)$ & 55.7 & 44.3 & $1.56(1.24-1.95)$ & $<0.001^{* * *}$ \\
\hline \multicolumn{6}{|l|}{ Age (years) } \\
\hline $60-69$ & $914(68.4)$ & 60.8 & 39.2 & & \\
\hline 70-79 & $312(23.4)$ & 58.0 & 42.0 & $1.12(0.87-1.46)$ & 0.38 \\
\hline$\geq 80$ & $110(8.2)$ & 59.1 & 40.9 & $1.08(0.72-1.61)$ & 0.72 \\
\hline \multicolumn{6}{|l|}{ Status } \\
\hline Single & $46(3.4)$ & 60.9 & 39.1 & & \\
\hline Married & $826(61.8)$ & 61.1 & 39.0 & 0.99 (0.54-1.82) & 0.97 \\
\hline Widowed & $411(30.8)$ & 57.9 & 42.1 & $1.13(0.61-2.11)$ & 0.70 \\
\hline Divorce/separated & $53(4.0)$ & 58.5 & 41.5 & $1.10(0.49-2.47)$ & 0.81 \\
\hline \multicolumn{6}{|l|}{ Education level } \\
\hline$\leq$ Primary school & $138(10.3)$ & 78.3 & 21.7 & & \\
\hline Secondary school & $830(62.1)$ & 62.3 & 37.7 & $2.18(1.42-3.34)$ & $<0.001^{* * *}$ \\
\hline Diploma & $210(15.7)$ & 51.9 & 48.1 & $3.34(2.05-5.42)$ & $<0.001^{* * *}$ \\
\hline College and above & $158(11.8)$ & 43.0 & 57.0 & $4.76(2.85-7.96)$ & $<0.001^{* * *}$ \\
\hline \multicolumn{6}{|l|}{ Living situation } \\
\hline Alone & $62(4.6)$ & 74.2 & 25.8 & & \\
\hline Living with family & $1274(95.4)$ & 59.3 & 40.7 & $1.97(1.10-3.52)$ & $0.02 *$ \\
\hline \multicolumn{6}{|l|}{ Health condition } \\
\hline Disease & $629(47.1)$ & 62.0 & 38.0 & & \\
\hline No disease & 707 (52.9) & 58.3 & 41.7 & 1.17 (0.94-1.46) & 0.17 \\
\hline \multicolumn{6}{|l|}{ Dependent on others } \\
\hline Yes & $92(6.9)$ & 55.4 & 44.6 & & \\
\hline No & $1244(93.1)$ & 60.4 & 39.6 & $0.82(0.53-1.25)$ & 0.35 \\
\hline \multicolumn{6}{|c|}{$\begin{array}{l}\text { Knowledge about food } \\
\text { consumption behaviours }\end{array}$} \\
\hline Fair or poor & $613(45.9)$ & 71.1 & 28.9 & & \\
\hline Good & $723(54.1)$ & 50.6 & 49.4 & $2.4(1.91-3.02)$ & $<0.001^{* * *}$ \\
\hline \multicolumn{6}{|c|}{$\begin{array}{l}\text { Attitude towards food } \\
\text { consumption behaviours }\end{array}$} \\
\hline Fair or poor & 499 (37.4) & 73.8 & 26.3 & & \\
\hline Good & $837(62.7)$ & 51.9 & 48.2 & $2.61(2.05-3.32)$ & $<0.001^{* * *}$ \\
\hline \multicolumn{6}{|l|}{ Food preference } \\
\hline Fair or poor & 779 (58.3) & 73.3 & 26.7 & & \\
\hline Good & $557(41.7)$ & 41.5 & 58.5 & 3.87 (3.07-4.88) & $<0.001^{* * *}$ \\
\hline \multicolumn{6}{|l|}{ Socio-economic factors } \\
\hline \multicolumn{6}{|l|}{ Income (Thai Baht) } \\
\hline$\leq 3000$ & $681(51.0)$ & 62.3 & 37.7 & & \\
\hline $3001-6000$ & $224(16.8)$ & 62.1 & 38.0 & $1.01(0.74-1.38)$ & 0.96 \\
\hline $6001-9000$ & $169(12.7)$ & 68.1 & 32.0 & 0.77 (0.54-1.11) & 0.16 \\
\hline$>9000$ & $262(19.6)$ & 47.3 & 52.7 & $1.84(1.38-2.45)$ & $<0.001^{* * *}$ \\
\hline
\end{tabular}


Table 2. Distribution of factors and binary logistic regression of factors influencing food consumption behaviours $(N=1,336)$ [Cont'd]

\begin{tabular}{|c|c|c|c|c|c|}
\hline \multirow[b]{2}{*}{ Factors } & \multirow[b]{2}{*}{$n(\%)$} & \multicolumn{2}{|c|}{ Behaviour } & \multirow{2}{*}{$\begin{array}{c}\text { Good behaviour } \\
\text { Crude OR } \\
(95 \% \text { CI) }\end{array}$} & \multirow[b]{2}{*}{ p-value } \\
\hline & & $\begin{array}{c}\text { Good } \\
\%\end{array}$ & $\begin{array}{c}\text { Fair or poor } \\
\%\end{array}$ & & \\
\hline \multicolumn{6}{|l|}{ Sufficient income } \\
\hline Inadequate & 419 (31.4) & 65.2 & 34.8 & 1 & \\
\hline Adequate & 917 (68.6) & 57.7 & 42.3 & $1.37(1.08-1.74)$ & $0.01^{*}$ \\
\hline \multicolumn{6}{|l|}{$\begin{array}{l}\text { Number of family } \\
\text { members }\end{array}$} \\
\hline 1 & $57(4.3)$ & 73.7 & 26.3 & 1 & \\
\hline 2 & $151(11.3)$ & 55.6 & 44.4 & $2.23(1.14-4.37)$ & $0.02^{*}$ \\
\hline 3 & $624(46.7)$ & 60.6 & 39.4 & $1.82(0.99-3.36)$ & 0.05 \\
\hline 4 & $374(28.0)$ & 57.0 & 43.1 & $2.11(1.13-3.95)$ & $0.02 *$ \\
\hline$\geq 5$ & $130(9.7)$ & 65.4 & 34.6 & $1.48(0.74-2.96)$ & 0.27 \\
\hline \multicolumn{6}{|l|}{ Family caretaking } \\
\hline $\begin{array}{l}\text { Family members care } \\
\text { for the elderly }\end{array}$ & 719 (53.8) & 62.7 & 37.3 & 1 & \\
\hline Taking care of family & 617 (46.2) & 56.9 & 43.1 & $1.28(1.02-1.59)$ & $0.03 *$ \\
\hline \multicolumn{6}{|l|}{ Family relationship } \\
\hline poor & $23(1.7)$ & 65.2 & 34.8 & 1 & \\
\hline fair & $89(6.7)$ & 70.8 & 29.2 & $0.77(0.29-2.05)$ & 0.61 \\
\hline good & $1224(91.6)$ & 59.2 & 40.9 & $1.29(0.54-3.08)$ & 0.56 \\
\hline \multicolumn{6}{|l|}{ Food culture } \\
\hline Poor & $10(0.8)$ & 70.0 & 30.0 & 1 & \\
\hline Fair & $274(20.5)$ & 70.4 & 29.6 & $0.98(0.25-3.88)$ & 0.98 \\
\hline Good & $1052(78.7)$ & 57.2 & 42.8 & $1.74(0.45-6.78)$ & 0.42 \\
\hline \multicolumn{6}{|l|}{ Food sources } \\
\hline Own garden & $270(20.2)$ & 67.8 & 32.2 & 1 & \\
\hline Natural source & $120(9.0)$ & 71.7 & 28.3 & $0.83(0.52-1.33)$ & 0.44 \\
\hline Village market & 660 (49.4) & 55.6 & 44.4 & $1.68(1.25-2.26)$ & $0.001^{* *}$ \\
\hline Town market & 186 (13.9) & 48.4 & 51.6 & $2.24(1.53-3.30)$ & $<0.001^{* * *}$ \\
\hline Mobile grocery truck & $88(6.6)$ & 80.7 & 19.3 & $0.50(0.28-0.91)$ & $0.02 *$ \\
\hline Department store & $12(0.9)$ & 41.7 & 58.3 & $2.94(0.91-9.54)$ & 0.07 \\
\hline \multicolumn{6}{|l|}{ Food factors } \\
\hline Poor & $115(8.6)$ & 71.3 & 28.7 & 1 & \\
\hline Fair & $158(11.8)$ & 74.7 & 25.3 & $0.84(0.49-1.45)$ & 0.53 \\
\hline Good & $1063(79.6)$ & 56.6 & 43.4 & $1.90(1.25-2.90)$ & $0.003^{* *}$ \\
\hline \multicolumn{6}{|l|}{ Health information } \\
\hline Yes & $1242(93.0)$ & 59.8 & 40.2 & 1 & \\
\hline No & $94(7.0)$ & 62.8 & 37.2 & $0.88(0.57-1.36)$ & 0.58 \\
\hline
\end{tabular}

${ }^{*} p<0.05$

$* * p<0.01$

$* * * p<0.001$

consumption behaviours of the elderly were sex, education level, living situation, health condition, knowledge, attitude and preference of foods. Regarding socio-economic factors related to food consumption behaviours of elderly, these were income, sufficiency of income, number of family members, family caretakers, food sources and food factors, as shown in Table 2 . 
Table 3. Multiple logistic regression of factors associated with food consumption behaviours of the elderly residing in northeastern Thailand $(N=1,336)$

\begin{tabular}{|c|c|c|c|}
\hline \multirow{2}{*}{ Factors } & \multicolumn{3}{|c|}{ Good behaviour } \\
\hline & Adjusted OR & $95 \% C I$ & $p$-value \\
\hline \multicolumn{4}{|l|}{ Personal factors } \\
\hline \multicolumn{4}{|l|}{ Sex } \\
\hline Male & 1 & & \\
\hline Female & 1.59 & $1.23-2.05$ & $<0.001^{* * *}$ \\
\hline \multicolumn{4}{|l|}{ Education level } \\
\hline Primary school & 1 & & \\
\hline Secondary school & 1.51 & $0.94-2.43$ & 0.09 \\
\hline Diploma & 2.34 & $1.34-4.09$ & $0.003^{* *}$ \\
\hline College and above & 2.20 & $1.22-3.98$ & $0.009 * *$ \\
\hline \multicolumn{4}{|l|}{ Living situation } \\
\hline Alone & 1 & & \\
\hline Living with family & 2.21 & $1.14-4.28$ & $0.02 *$ \\
\hline \multicolumn{4}{|l|}{ Health condition } \\
\hline Disease & 1 & & \\
\hline No disease & 1.40 & $1.08-1.81$ & $0.01 *$ \\
\hline \multicolumn{4}{|l|}{$\begin{array}{l}\text { Knowledge about food consumption } \\
\text { behaviours }\end{array}$} \\
\hline Fair or poor & 1 & & \\
\hline Good & 2.00 & $1.51-2.64$ & $<0.001^{* * *}$ \\
\hline \multicolumn{4}{|l|}{$\begin{array}{l}\text { Attitude towards food consumption } \\
\text { behaviours }\end{array}$} \\
\hline Fair or poor & 1 & & \\
\hline Good & 1.82 & $1.37-2.43$ & $<0.001^{* * *}$ \\
\hline \multicolumn{4}{|l|}{ Food preference } \\
\hline Fair or poor & 1 & & \\
\hline Good & 3.28 & $2.55-4.22$ & $<0.001^{* * *}$ \\
\hline \multicolumn{4}{|l|}{ Socio-economic factors } \\
\hline \multicolumn{4}{|l|}{ Family caretaking } \\
\hline Family member care for the elderly & 1 & & \\
\hline $\begin{array}{l}\text { Elderly person taking care of his / } \\
\text { her family }\end{array}$ & 1.59 & $1.22-2.09$ & $0.001^{* *}$ \\
\hline \multicolumn{4}{|l|}{ Food sources } \\
\hline Own garden & 1 & & \\
\hline Wild source & 1.11 & $0.66-1.87$ & 0.69 \\
\hline Village market & 1.67 & $1.19-2.34$ & $0.003^{* *}$ \\
\hline Town market & 1.70 & $1.08-2.66$ & $0.02 *$ \\
\hline Mobile grocery truck & 0.69 & $0.36-1.31$ & 0.25 \\
\hline Department store & 1.10 & $0.30-4.07$ & 0.88 \\
\hline \multicolumn{4}{|l|}{ Food factors } \\
\hline Poor & 1 & & \\
\hline Fair & 1.04 & $0.57-1.90$ & 0.90 \\
\hline Good & 2.37 & $1.47-3.81$ & $<0.001^{* * *}$ \\
\hline
\end{tabular}

${ }^{*} p<0.05$

$* * p<0.01$

$* * * p<0.001$ 
These variables were analysed together by using multiple logistic regression analysis, while controlling for other variables. It was found that personal factors related to food consumption behaviours of the elderly in the Northeastern region included sex $(p<0.001)$, education level $(p<0.01)$, living situation $(p=0.02)$, health condition $(p=0.01)$, knowledge $(p<0.001)$, attitude $(p<0.001)$ and preference of foods $(p<0.001)$. Socio-economic factors related to food consumption behaviours of the elderly in the Northeastern region were family caretakers $(p=0.001)$, food sources $(p<0.05)$ and food factors $(p<0.001)$, as shown in Table 3.

\section{DISCUSSION}

Food consumption behaviours of majority of the elderly in the Northeastern region were in the fair or poor levels, which were in accordance with a previous research about the elderly in Burirum (ManLuan et al., 2019). From this research, it was found that food preferences of the elderly had a statistical significance with their food consumption behaviours. The reason might have stemmed from the development of their food preferences during childhood. The elderly tended to like foods that they had liked when they were young. Their food consumption behaviours, which was in an unsatisfactory level, was also about putting seasoning powder in their foods. It was believed that the reason they did this was because they believed that it would make their foods more delicious (Pruksa \& Sookprasert, 2018; Pruksa \& Sripoona, 2017).

The results from this research demonstrated that sex and education level were associated with food consumption behaviours among the elderly. It has previously been suggested that women tend to take better care of themselves than men as they are more concerned with the nutritional facts of foods (Stran \& Knol., 2013; Sawangsri \& Tangngam, 2013; Westenhoefer, 2015). In addition, elderly with a higher level of education generally have better knowledge on health, thus leading to better food consumption behaviours (McCracken \& Phillips, 2012).

It was also found that the elderly who lived with their children or relatives were 2.20 times more likely to have a good level of food consumption behaviours than those who did not live with their children or relatives. The reason was that in a family, they lived together and helped each other, and therefore had a better quality of life (Sasuad, 2017). Furthermore, in this research, it was found that food consumption behaviours in the elderly who did not have any diseases were better than those who had diseases. The reason could be either people who made healthier choices that resulted in better health or people who had better health ate better because they were less debilitated, or both (Pinho et al., 2018). This was in accordance with a previous study showing that physical and mental health influenced food consumption behaviours of the elderly (Pui-ngam, 2010).

This study found that the elderly's knowledge about food and nutrition reached a good level, and it was 2 times higher than those who had a fair or poor level of knowledge. This showed that they knew what was good or not good for their bodies, and the effects towards their bodies (Loyola, 2010). They had good understanding and perception towards food and nutritional values, and that improved their food consumption behaviours (Brown, 2004). Moreover, the elderly's attitude towards food consumption was within a good range, which was 1.82 times higher than those who had a fair or poor attitude towards food consumption. It could be that the elderly 
who had a good attitude towards food consumption also had good knowledge about food consumption (Chumkaew \& Rungsayatorn, 2014). With respect to food preference, it was also significantly related to food consumption behaviours of the elderly in the Northeastern region. Elderly who had a good food preference had food consumption behaviour score that was 3.28 times higher than those who had a poor food preference. This may be because the elderly experience physical and mental changes which decrease their appetite. They do not feel like eating so they choose only what they want (Department of Older Person, 2017), thus, their food consumption behaviours reflected what they liked.

The socio-economic factors related to food consumption behaviours of the elderly in the Northeastern region included family caretaking, food sources and food factors. Elderly who took care of their family had better food consumption behaviours than those who were taken care of by their children. This was the same as a study by Sriugsorn $\&$ Kanjanawasee (2009), which found that family support was related to the food consumption behaviours of elderly in Bangkok. The reason was because most elderly in this research had a diploma level education and had better food factors than those elderly who were taken care of by their children. Furthermore, the elderly who took care of their family could still help themselves and could cook foods by themselves. Therefore, they were able to choose quality foods. Meanwhile, the elderly who were taken care of by their children had to eat with their children and they could not choose the foods they wanted. As a result, if the elderly's children or caretakers did not pay attention to their food consumption behaviours, the elderly might have problems in the future.

With respect to food sources, it was found that they were significantly related to the food consumption behaviours of the elderly in the Northeastern region. Food consumption behaviours of the elderly who bought foods from their village market was better than those who grew their own foods. A similar finding was obtained for the elderly who bought foods from the market in town versus the elderly who grew their own foods. The reason for these findings was that the market offered a wider variety of foods (Phumee \& Thomol, 2017). During the survey, it was noted that there was a small market in the village where local people went to purchase some of their foods. Similarly, Wannawong (2009) found that sources of foods and food prices were significantly related to food consumption behaviours among the elderly in Yasothon, a city in the Northeastern region. The elderly who had good food factors had 2.37 times better food consumption behaviour than those who did not. These good food factors included food access, good quality of foods and reasonable prices. This result was in accordance with the outcome of a study by Warathornpiboon (2014), which showed that food price was an important determinant of food consumption behaviours. If food price was too high, food choices were limited and this resulted in poorer food quality among elderly consumers. Moreover, the quantity of foods in the market was another important factor related to food consumption behaviours. If there was sufficient food for people in a community, it could be said that the community had good food access and people had a better chance of choosing their foods (Warathornpiboon, 2014).

\section{CONCLUSION}

The results from this research found that sex, education level, living situation, health condition, knowledge, attitude, food preferences, family caretaking, 
food sources and food factors were significantly associated with food consumption behaviours among the elderly in the Northeastern region of Thailand. Consequently, activities about food consumption behaviours of the elderly in the Northeastern region should be focused on small groups and the elderly with lesser formal education (lower than primary level), living alone and those having diseases, because these individuals have lower food consumption behaviours compared with elderly who stayed with their children and relatives, those who were married, and those who were generally healthy. People who work in the nutrition office and related offices, such as the municipal office and public health office, should pay more attention to food sources for the elderly. There should be enough markets, with sufficient food variety, for the elderly. Some elderly have low incomes, while some can grow their own foods with more variety and abundance. As a result, household vegetable production, small scale animal rearing, and preservation of natural resources should be promoted in parallel so that the elderly can have access to these food sources. The quality of foods and food prices should also be constantly checked so that the elderly can access sufficient amounts of good quality and sustainably-produced foods.

\section{Acknowledgements}

I am grateful to the volunteers for their kind cooperation and the Food and Nutrition Policy for Health Promotion in Thailand for financial support.

\section{Authors' contributions}

PS, principal investigator, conceptualised and designed the study, data collection, data analysis and interpretation, prepared the draft of the manuscript and reviewed the manuscript.

\section{Conflict of interest}

I declare that I have no conflict of interest.

\section{References}

Aekplakorn W (ed) (2014). Thai national health examination survey. 5th Ed. Health System Research Institute, Nontaburi.

Aekplakorn W \& Satheannoppakao W (eds) (2012). Thailand national food consumption survey Thai national health examination survey. 4th Ed. Health System Research Institute, Nontaburi.

Ahmed T \& Haboubi N (2010). Assessment and management of nutrition in older people and its importance to health. Clin Interv Aging 5:207-216.

Best JW (1977). Research in Education. 3rd Ed. Prentice Hall, Inc. Englewood Cliffs, New Jersey.

Bloom BS (1971). Hand Book on Formative and Summative Evaluation of Student Learning. Graw-Hill Book Company, New York.

Brown JE (2004). Nutrition Now. 4th Ed. Thomson Wadsworth, California.

Chumkaew K \& Rungsayatorn S (2014). Knowledge, attitude, and food consumption behaviour of the elderly in Songkhla province. Kasetsart $J$ Soc Sci 35(1): 16-29.

Department of Older Persons (2017). Handbook of self-care and potential development of elders for good health. Department of Older Persons, Ministry of Social Development and Human Security, Bangkok.

Foundation of Thai Gerontology Research and Development Institute (2017). Situation of the Thai elderly. Duantula Printing Public Company Limited, Bangkok.

Jones CM \& Boelaert K (2015). The endocrinology of ageing: a mini-review. Gerontology 61(4):291300 .

Kitreerawutiwong N \& Mekrungrongwong S (2016). Factor influencing health behaviour among elderly living in the community. The Public Health Journal of Burapha University 11(1):6374.

Loyola S (2010). Evidence-based teaching guideline: transforming knowledge into practice for better outcome in healthcare. Crit Care Nurs Q 33(1):19-32.

Manlaun K, Kanchanasit W \& Sutthipan N (2019). The Elderly Health Behaviour in Bannongprong District Health Promotion Hospital, Amphoe Mueang, Burirum Province. The $6^{\text {th }}$ International Conference Nakhonrajchasrima College. From http://www.journal.nmc.ac.th/th/ showcontinue.php?idj=51 [Retrieved March 1, 2020]. 
McCracken K \& Phillips DR (2012). Global health: An introduction to current and future trends. Routledge, New York.

Phumee P \& Thomol P (2017). Biodiversity and utilizing benefit of wild food plants in Isan local markets: a case study in Huai Luang basin area of northeastern Thailand. Mekong Chi Mun Art and Culture Journal 3(1):187-212.

Pinho MGM, Mackenbach JD, Charreire H, Oppert JM, Bárdos H, Glonti K, Rutter H, Compernolle S, De Bourdeaudhuij I, Beulens JWJ, Brug J \& Lakerveld J (2018). Exploring the relationship between perceived barriers to healthy eating and dietary behaviours in European adults. Eur J Nutr 57(5):1761-1770.

Pruksa S \& Sookprasert W (2018). Food consumption behaviours and nutrition status of the elderly in Na-o sub-district, Muang district, Loei province. Journal of the office of DPC 7 Khonkan 25(3):67-76.

Pruksa S \& Sripoona S (2017). Healthy food consumption behaviours of elderly in Na-O sub-district, Muang district, Loei province. Journal of Research and Development Institute Loei Rajabhat University 12(42):58-67.

Pui-ngam A (2010). Factors influencing food consumption behaviors of the elderly in Ban Sing subdistrict, Photharam district, Ratchaburi province. Ramkhamhaeng University, Bangkok.

Rauber E, Louzada MLC, Steele EM, Millett C, Monteiro CA \& Levy RB (2018). Ultraprocessed food consumption and chronic non-communicable diseases-related dietary nutrient profile in the UK (2008-2014). Nutrients 10(5):587.
Sangthong J (2017). Aging society (complete aged): the elderly condition of good quality. Rusamilae Journal 3(1):6-28.

Sasuad K (2017). Factors affecting the quality of life of the elderly in the eastern province. NRRU Community Research Journal 11(2):21-38.

Sawangsri B \& Tangngam S (2013). Self-healthcare of the elderly in Samchuk district, Suphanburi province. RMUTSB Acad J 1(2):128-137.

Sriugsorn T \& Kanjanawasee T (2009). Factors affecting food consumption behaviours of elders in Bangkok. Journal of Sports Science and Health 10(3):57-65.

Wannawong C (2009). Factors related to food consumption behaviours of the elderly in Muang district, Yaso thorn province (Master's thesis). Ramkahang University, Bangkok.

Warathornpiboon T (2014). Consumption behaviour: consumerism food and healthconscious food. Panyapiwat Journal 5(2):255264.

Westenhoefer J (2015). Age and gender dependent profile of food choice. Forum Nutrition 57:44-51.

Yakoh K (2017). Factors affecting food consumption behaviours of elderly in Makham Tia, Mueang district, Surat Thani province. Journal of Southern Technology 11(2):135-143. 